\title{
Fluctuation of Spastic Location in Patients With Vasospastic Angina: A Quantitative Angiographic Study
}

\author{
YUKIO OZAKI, MD, PHD, DAVID KEANE, MB, MRCPI, PHD, \\ PATRICK W. SERRUYS, MD, PHD, FACC
}

Rotterdam, The Netherlands

Objectives. This study sought to determine whether the location of coronary spastic activity may change over time in patients with persistent variant angina.

Background. Although electrocardiographic studies have provided indirect evidence to indicate that the location of ischemia may change in patients with variant angina, it has not been tested by quantitative angiography whether the location of vasospastic activity may change over time.

Methods. Paired ergonovine provocation tests and coronary angiography were performed at a mean ( \pm SD) interval of $43 \pm 13$ months apart in patients with persistent symptoms of vasospastic angina in the absence of significant atherosclerosis. $A$ total of 87 spastic and nonspastic segments of 87 major vessels in 29 patients were analyzed by quantitative angiography at baseline, after the administration of ergonovine and after isosorbide dinitrate at the initial and follow-up tests.

Results. In 13 patients (group 1), coronary spasm was observed

Coronary spasm plays a role in a wide spectrum of ischemic coronary events, including variant angina and some cases of unstable angina and acute myocardial infarction (1-13). Although vasospastic anginal symptoms have undergone spontaneous remission in some patients with variant angina (14-17), persistent symptoms have been observed over many years in other patients without significant atherosclerosis (17-20). Although Kaski et al. (21) observed that coronary spasm may remain active over years in the same coronary segments despite medical therapy, other investigators $(14,22,23)$ demonstrated variability of electrocardiographic (ECG) changes during repeated ergonovine tests and recurrent spontaneous attacks. However, whether the location and degree of vasospasm may change over a period of several years has not yet been established quantitatively.

From the Catheterization Laboratory, Department of Interventional Cardiology, Thoraxcenter, Erasmus University, Rotterdam, The Netherlands. Dr. Yukio Ozaki is the recipient of a grant from Takeda Medical Research (Taisha Ijo) Foundation, Osaka, Japan. Dr. David Keane is the recipient of a travel grant from the Peel Medical Research Trust, London, England, United Kingdom.

Manuscript received January 30. 1995: revised manuscript received July 11 1995, accepted July 24, 1995.

Address for correspondence: Dr. Patrick W. Serruys, Thoraxcenter, Erasmus University, P.O. Box 1738. 3000 DR Rotterdam. The Netherlands. in the same $\mathbf{1 6}$ coronary segments at both the initial and follow-up ergonovine provocation tests. In 16 patients (group 2), the following angiographic changes occurred between the initial and follow-up tests in 48 major vessels: Of the 23 segments that developed spasm at the initial test, 10 did not have spasm at the follow-up test; of the 25 vessels that did not demonstrate spasm on the initial test, 12 demonstrated spasm on the follow-up test (a new site of spasm). Thus, in $22(46 \%)$ of 48 vessels, fluctuation of spastic location was observed at follow-up.

Conclusions. Quantitative coronary angiography and repeated ergonovine tests revealed that some patients with persistent vasospastic angina demonstrate fluctuation of vasospastic location, whereas others exhibit a fixed location of vasospasm. Vasospastic angina may not only be a transient disease restricted in location, but may also be a persistent and variable condition involving multiple vessels over many years.

(J Am Coll Cardiol 1995;26:1606-14)

Although many clinical studies $(4,6,8,9,15,21)$ have shown that coronary spasm frequently occurs at sites of advanced atherosclerosis, Conti et al. (7) suggested that the presence of significant atherosclerosis may reduce the role of vasospasm in ischemic attacks. To determine the long-term role of vasospastic activity and its variation in location, we repeated ergonovine provocation tests in patients without advanced atherosclerosis but with persistent symptoms of variant angina at an average interval of 43 months apart, using a computer-based quantitative coronary angiographic analysis system (CAAS II).

\section{Methods}

Criteria of vasospastic angina. The following criteria of vasospastic angina were used: 1) chest pain at rest associated with ST segment changes $>0.2 \mathrm{mV}$ on the ECG; 2) pain relief immediately after administration of nitroglycerin; 3 ) no subsequent evidence of myocardial infarction; 4) ergonovineprovoked coronary spasm associated with chest pain and ischemic ECG changes. Coronary spasm was defined as 1) a transient total or nearly total occlusion reversible with isosorbide dinitrate, or 2$)$ a transient, significant $(>50 \%)$ narrowing reversible with isosorbide dinitrate in normal or nearly normal segments (24-26). We used the ergonovine provocation test because it has been found (27-29) to have a high sensitivity and 
Table 1. Clinical and Angiographic Characteristics of 29 Patients With Vasospastic Angina

\begin{tabular}{|c|c|c|c|c|c|}
\hline \multirow[b]{2}{*}{ Pt No. } & \multirow{2}{*}{$\begin{array}{l}\text { Age }(y r) \\
\text { Gender }\end{array}$} & \multicolumn{2}{|c|}{ ST Segment Changes During Spasm } & \multicolumn{2}{|c|}{ Percent Fixed Stenosis at Spastic Site After ISDN } \\
\hline & & Initial ECG & Follow-Up ECG & Initial Angiogram & Follow-Up Angiogram \\
\hline \multicolumn{6}{|l|}{ Group 1} \\
\hline 1 & $56 / \mathrm{M}$ & III, a VF & III, aVF & $21 \%$ seg 1 & $15 \%$ seg 1 \\
\hline 2 & $63 / \mathrm{M}$ & $V_{2}-V_{4}$ & $V_{2}-V_{4}$ & $45 \%$ seg 7 & $41 \% \operatorname{seg} 7$ \\
\hline 3 & $63 / \mathrm{M}$ & Il, III, a VF & II, III, aVF & $35 \% \operatorname{seg} 11$ & $38 \%$ seg 11 \\
\hline 4 & $67 / \mathrm{M}$ & II. III, aVF & II, III, aVF & $22 \% \operatorname{seg} 2,27 \%$ seg 13 & $16 \%$ seg $2,31 \% \operatorname{seg} 13$ \\
\hline 5 & $49 / \mathrm{M}$ & III. aVF. $V_{3}-V_{5}$ & III, aVF, $V_{3}-V_{5}$ & $19 \% \operatorname{seg} 2,34 \% \operatorname{seg} 6$ & $31 \%$ seg $2,27 \%$ seg 6 \\
\hline 6 & $57 / \mathrm{M}$ & II, III, aVF & II, III, a VF & $28 \% \operatorname{seg} 2$ & $24 \% \operatorname{seg} 2$ \\
\hline 7 & $61 / \mathrm{M}$ & II. III, aVF, $V_{t}$ & II, III, aVF, $V_{t}$ & $42 \%$ seg $1,29 \%$ seg 13 & $28 \% \operatorname{seg} 1,15 \% \operatorname{seg} 13$ \\
\hline 8 & $54 / \mathrm{M}$ & II, III, aVF & II, III, aVF & $22 \% \operatorname{seg} 2$ & $27 \% \operatorname{seg} 2$ \\
\hline 9 & $55 / \mathrm{M}$ & II, III, aVF & II, III, aVF & $18 \% \operatorname{seg} 1$ & $15 \% \operatorname{seg} 1$ \\
\hline 10 & $41 / \mathrm{M}$ & $V_{2}-V_{4}$ & $V_{2}-V_{4}$ & $24 \% \operatorname{seg} 7$ & $28 \% \operatorname{seg} 7$ \\
\hline 11 & $57 / \mathrm{M}$ & II, III, aVF, V, & II, III, aVF, $V_{t}$ & $31 \% \operatorname{seg} 13$ & $22 \%$ seg 13 \\
\hline 12 & $48 / \mathrm{F}$ & IIl, aVF, $V_{t}$ & III, aVF, $V_{6}$ & $49 \% \operatorname{seg} 13$ & $39 \% \operatorname{seg} 13$ \\
\hline 13 & $54 / \mathrm{M}$ & II, III, aVF & II, III, aVF & $3 \%$ seg 1 & $25 \%$ seg 1 \\
\hline \multicolumn{6}{|l|}{ Group 2} \\
\hline 14 & $62 / \mathrm{M}$ & $V_{2}+V_{4}$ & II, III, aVF & $42 \% \operatorname{seg} 7.18 \% \operatorname{seg} 13$ & $13 \% \operatorname{seg} 13$ \\
\hline 15 & $57 / \mathbf{F}$ & II, III, aVF & II, III, $V_{2}-V_{s}$ & $17 \% \operatorname{seg} 3$ & $13 \% \operatorname{seg} 2,29 \%$ seg $7,25 \%$ seg 13 \\
\hline 16 & $54 / \mathrm{M}$ & II, III, aVF, $V_{3}-V_{4}$ & II, III, aVF & $29 \%$ seg $1,19 \%$ seg $7,23 \%$ seg 11 & $39 \% \operatorname{seg} 1$ \\
\hline 17 & $42 / \mathrm{M}$ & $v_{2}-V_{5}$ & II, III, aVF & $25 \%$ seg 7 & $16 \% \operatorname{seg} 3$ \\
\hline 18 & $52 / \mathrm{M}$ & IlI, aVF, $V_{2}-V_{s}$ & II, III, aVF & $7 \% \operatorname{seg} 4,14 \% \operatorname{seg} 7$ & $20 \% \operatorname{seg} 4,21 \% \operatorname{seg} 11$ \\
\hline 19 & $56 / \mathrm{M}$ & $V_{3}-V_{4}$ & Il, III, $V_{3}-V_{4}$ & $17 \% \operatorname{seg} 7$ & $14 \%$ seg $1,47 \%$ seg 7 \\
\hline 20 & $68 / \mathrm{M}$ & [II. aVF & III, aVF, $V_{2}-V_{4}$ & $30 \% \operatorname{seg} 11$ & $20 \% \operatorname{seg} 6,36 \% \operatorname{seg} 11$ \\
\hline 21 & $58 / \mathbf{F}$ & II, III. aVF & II, III, aVF, $V_{2}-V_{s}$ & $20 \% \operatorname{seg} 4$ & $25 \% \operatorname{seg} 4,25 \% \operatorname{seg} 7$ \\
\hline 22 & $62 / \mathrm{M}$ & II, III, aVF & II. III, aVF, $V_{t}$ & $9 \% \operatorname{seg} 2,29 \% \operatorname{seg} 13$ & $42 \%$ seg 13 \\
\hline 23 & $66 / \mathrm{M}$ & III, aVF, $V_{4}-V_{5}$ & II, III, aVF & $13 \% \operatorname{seg} 3,17 \% \operatorname{seg} 13$ & $36 \% \operatorname{seg} 13$ \\
\hline 24 & $44 / \mathrm{M}$ & $V_{2}-V_{i}$ & II, III, aVF & $2 \% \operatorname{seg} 2,29 \% \operatorname{seg} 6$ & $19 \% \operatorname{seg} 2$ \\
\hline 25 & $50 / \mathrm{M}$ & $V_{1}-V_{t}$ & II. III, aVF & $7 \%$ seg 6 & $24 \% \operatorname{seg} 2$ \\
\hline 26 & $61 / \mathrm{M}$ & II, III. aVF & II, III, aVF, $V_{2}-V_{4}$ & $16 \% \operatorname{seg} 2$ & $19 \%$ seg $1,29 \%$ seg 7 \\
\hline 27 & $37 \mathrm{M}$ & II, III, aVF & II, III, aVF, $V_{0}$ & $17 \%$ seg 1 & $31 \%$ seg $1,6 \%$ seg 13 \\
\hline 28 & $46 \mathrm{M}$ & $V_{2}-V_{5}, I, a V I$ & II, III, aVF & $48 \% \operatorname{seg} 6$ & $45 \%$ seg 2 \\
\hline 29 & $43 / \mathrm{M}$ & AVI. $V_{5}-V_{0}$ & II, III, aVF, $V_{\mathrm{t}}$ & $18 \% \operatorname{seg} 11$ & $6 \%$ seg $3,26 \%$ seg 11 \\
\hline
\end{tabular}

ECG = electrocardiogram; $F=$ temale: ISDN = isosorbide dinitrate; $M=$ male: $\mathrm{Pt}=$ patient; seg = coronary segment as defined by the American Heart Association classification (43).

specificity for, and short-term reproducibility of, spontaneous anginal attacks in patients with vasospastic angina. Follow-up angiography and provocation testing were performed to estimate the progression of atherosclerosis as well as to determine the location of vasospastic activity and to provide information on the necessity to continue long-term medication.

Study patients. Because the purpose of the present study was to examine the role of pure vasospasm in ischemic attacks during long-term follow-up, we excluded patients with significant atherosclerosis ( $>50 \%$ diameter stenosis after administration of isosorbide dinitrate). The study group was selected from a total of 50 patients with variant angina who had undergone long-term angiographic and ergonovine provocation follow-up. Of the 50 patients who had chest pain at rest with ischemic ST segment changes at the time of the initial angiographic study, vasospastic anginal symptoms were persistent during the follow-up period in 34 . In the remaining 16 patients, symptoms of vasospastic angina resolved during follow-up, and these 16 patients were excluded from the study. Of the former 34 patients, 5 who developed significant, fixed stenosis $(>50 \%$ diameter stenosis after administration of isosorbide dinitrate) during follow-up were excluded from the study. Of the remaining 29 patients, 13 had persistent symptoms of vasospastic angina with ischemic ST segment changes during the follow-up period, and vasospasm was reproduced at the same coronary segment at the follow-up angiogram (group 1); 16 patients had persistent symptoms of vasospastic angina with ischemic ST segment changes during the follow-up period, and vasospasm occurred in different vessels at follow-up (group 2).

Ischemic episode during follow-up. Vasospastic anginal activity was assessed by anginal symptoms, 12-lead ECG monitoring during anginal attacks and ambulatory in-hospital ECG monitoring or Holter monitoring out of hospital in all patients. All 29 patients had intermittent chest pain with ST segment changes at the time of the initial angiographic study (Table 1). These attacks were frequently observed over a period of a few days to several weeks (so-called hot phases of the disease [21]). The medication, combined with a calcium antagonist (diltiazem) and sustained-release isosorbide dinitrate (Table 2), was effective and reduced the frequency of ischemic attacks in both groups; however, vasospastic angina 
Table 2. Clinical Characteristics of Groups 1 and 2

\begin{tabular}{lccc}
\hline & $\begin{array}{c}\text { Group 1 } \\
(\mathrm{n}=13)\end{array}$ & $\begin{array}{c}\text { Group 2 } \\
(\mathrm{n}=16)\end{array}$ & $\begin{array}{c}\mathrm{p} \\
\text { Value }\end{array}$ \\
\hline Age (yr) & $56 \pm 7$ & $54 \pm 9$ & 0.50 \\
M/F & $12 / 1$ & $14 / 2$ & 0.85 \\
Coronary risk factors & & & \\
$\quad$ Hypertension & 2 & 3 & 0.80 \\
$\quad$ Diabetes & 1 & 1 & 0.56 \\
Smoking & 12 & 14 & 0.85 \\
$\quad$ Hypercholesterolemia & 1 & 1 & 0.55 \\
Serum cholesterol (mg/day) & $191 \pm 33$ & $188 \pm 28$ & 0.82 \\
Initial test & $197 \pm 39$ & $194 \pm 29$ & 0.81 \\
Follow-up test & & & \\
Interval of tests (mo) & 2 & 2 & 0.85 \\
$20-29$ & 3 & 5 & 0.94 \\
$30-39$ & 2 & 6 & 0.36 \\
$40-49$ & 3 & 2 & 0.80 \\
$50-59$ & 3 & 1 & 0.44 \\
$60-69$ & $46 \pm 15$ & $41 \pm 11$ & 0.39 \\
Mean & $212 \pm 31$ & $203 \pm 35$ & 0.44 \\
Calcium antagonist (diltiazem) (my/day) & $57 \pm 8$ & $58 \pm 7$ & 0.83 \\
Sustained-release ISDN (mg/day) &
\end{tabular}

Data presented are mean value $=\mathrm{SD}$ or number of patients, unless otherwise indicated. Abbreviations as in Table 1.

persisted throughout the follow-up period. Over the follow-up period, 22 of the 29 patients had a second or a third hot phase. During the repeated hot phases, all 22 patients required readmission and showed frequent ischemic episodes of ST segment changes recorded on ambulatory ECG monitoring or rest 12-lead ECG monitoring in hospital. Of the remaining seven patients who did not experience a repeated hot phase but had regular vasospastic anginal attacks, three showed SI segment elevation during an exercise test early in the morning, and four had ST segment elevation on Holter monitoring out of hospital during follow-up.

Angiographic procedure. The present study was approved by the hospital ethics committee, and written informed consent was obtained from each patient. All patients were admitted to the coronary care unit before the study. Sublingual nitroglycerin was administered as required, but calcium antagonists and oral nitrates were gradually tapered, and calcium antagonists were discontinued for $36 \mathrm{~h}$ and oral nitrates for $24 \mathrm{~h}$ before the study. Coronary angiography was performed in the morning (from 8:30 AM to 11 AM) by the Sones technique at Anjo Kosei Hospital in Japan. After baseline angiograms suitable for quantitative analysis of the right and left coronary arteries had been obtained, $0.2 \mathrm{mg}$ of ergonovine maleate was administered intravenously by a rapid bolus injection. Radiographic projections were identical during the sequential angiographic studies. Heart rate and aortic pressure were monitored continuously, and 12 -lead ECGs were recorded at 30-s intervals. Whenever chest pain or significant ST segment changes were observed, selective coronary angiograms were immediately obtained. Coronary vasospasm was relieved by isosorbide dinitrate, given as one or two intracoronary boluses to a total of $5 \mathrm{mg}$. To exclude the possibility of persistent spasm. we gave a dose
( $5 \mathrm{mg}$ ) of intracoronary isosorbide dinitrate that was greater than the dose previously demonstrated $(30,31)$ to achieve maximal coronary vasodilation in patients with vasospastic angina $(3 \mathrm{mg})$. The follow-up angiogram was obtained in the same angiographic projection as the initial angiogram after viewing the initial angiographic records and cine film. Then, the response to ergonovine and the severity of fixed stenoses were quantified in the matched views of the initial and follow-up angiograms using the quantitative angiographic analysis system. No complications occurred during the repeated ergonovine provocation tests and the angiographic procedures.

Quantitative coronary angiographic analysis. The new version of the computer-based coronary angiography analysis system (CAAS II) $(32,33)$ was used to perform the quantitative analysis in a core angiographic laboratory (Cardialysis, Rotterdam, The Netherlands). The CAAS analysis has been described in detail elsewhere (33-39). Briefly, the entire cine frame of $18 \times 24 \mathrm{~mm}$ is digitized at a resolution of $1,329 \times$ 1,772 pixels. Correction for pin-cushion distortion is performed before analysis. Boundaries of a selected coronary segment are detected automatically. The absolute diameter of the stenosis in millimeters is determined using the guiding catheter as a scaling device (40). To standardize the method of analysis of the initial and follow-up angiograms, all study frames selected for analysis were end-diastolic to minimize motion artifact, and arterial segments were measured between the same identifiable branch points at baseline, after administration of ergonovine and after administration of isosorbide dinitrate $(41,42)$.

In the CAAS II system (32-42), minimal lumen diameter was determined by computer-based edge-detection contour using minimal cost criteria. The CAAS II system determines the size at the target coronary segment using a computerderived interpolated reference diameter rather than an operatorselected reference point. The interpolated reference diameter is derived from the edge-detection diameter function of the nonstenotic/nonspastic proximal and distal subsegments. The reference vessel diameter values are estimated by fitting a straight line to the diameter function proximal and distal to the obstruction followed by a shift such that $80 \%$ of the diameter values are below the adjusted straight line. This line then represents the reconstructed reference diameter function and gives an estimate of the arterial size at each point along the analyzed coronary segment. The interpolated reference vessel diameter is taken as the value of the reconstructed diameter function at the position of the minimal lumen diameter. The advantages of this approach are that it is essentially user independent, and thus highly reproducible, and that every measurement is based on multiple measurements (every scan line) proximal and distal to the lesion.

Segments analyzed. The coronary segments were coded according to the recommendations of the American Heart Association (AHA) (43). One AHA segment from each of the three major epicardial vessels was analyzed. For vessels that demonstrated vasospasticity, the segment in which vasospasm occurred was analyzed. For vessels in which no vasospasm 
Figure 1. Reference (dotted line) and minimal lumen diameter (solid line) changes at baseline and after administration of ergonovine and isosorbide dinitrate (ISDN) at both initial and follow-י p angiography in group 1. A, After administration of ergonovine, minimal lumen diameter constricted significantly in 16 spastic segments of 16 vessels at both the initial and follow-up tests. B, Reference and minimal lumen diameter responses to ergonovine were equivalent in 23 nonspastic segments of 23 vessels at both the initial and follow-up tests.

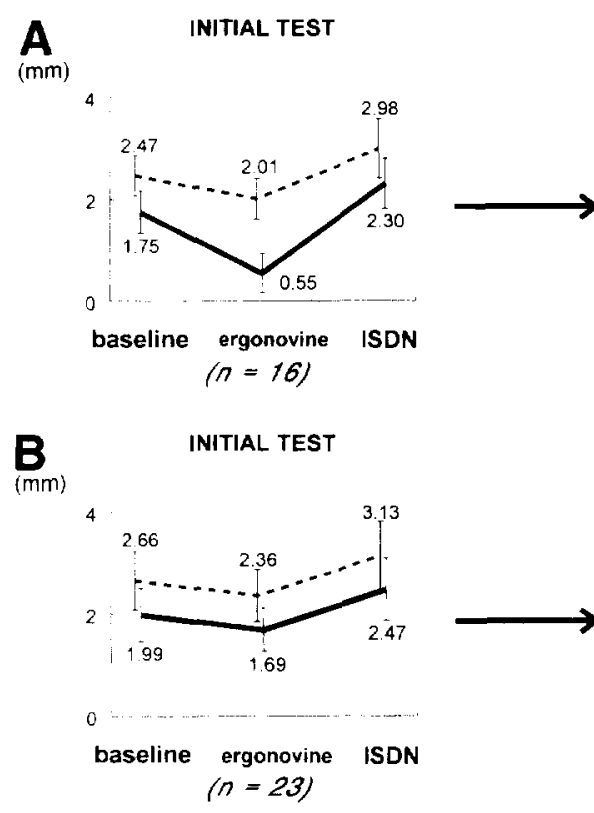

FOLLOW-UP TEST

(mm)

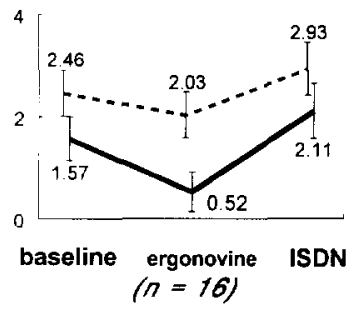

FOLLOW-UP TEST

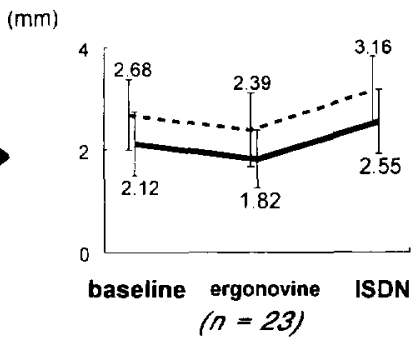

occurred, the AHA segment analyzed was that which had the most diseased appearance. Quantitative angiographic analysis provided the minimal lumen and reference vessel diameters for all AHA segments analyzed.

Statistical analysis. The unpaired Student $t$ test was used to compare the two groups of patients. Differences between proportions were analyzed by the chi-square test with correction; $\mathrm{p}<0.05$ was considered significant.

\section{Results}

Clinical characteristics. All patients demonstrated persistent symptoms of vasospastic angina with ischemic ST segment changes during follow-up that were detected by in-hospital 12-lead or ambulatory ECG monitoring. or both, or Holter monitoring out of hospital. Medication was a combination of a calcium antagonist (diltiazem) and sustained-release isosorbide dinitrate. Although the medication reduced the frequency of ischemic attacks, symptoms of variant angina persisted throughout the follow-up period.

The ECG and angiographic results for all 29 patients are presented in Table 1. The location of myocardial ischemia indicated by ECG changes and the spastic coronary segment shown by angiography were similar at the initial and follow-up tests in 13 patients (group 1, Patients 1 to 13) but were different at follow-up in 16 (group 2, Patients 14 to 29). With regard to clinical characteristics, no significant differences were found between groups 1 and 2 for age ( $56 \pm 7$ vs. $54 \pm 9$ years); gender ( 1 of 13 vs. 2 of 16 female patients); coronary risk factors, such as hypertension, diabetes, smoking and hypercholesterolemia; and average serum cholesterol level (Table 2). The mean interval to angiographic follow-up ( $46 \pm 15 \mathrm{vs.} 41 \pm$ 11 months) was similar in the two groups, and there was no significant difference in medication.
Location of coronary spasm. In group 1, no fluctuation in location of vasospasticity was observed at follow-up. In group 2 , fluctuation of spastic location was observed at follow-up in $22(46 \%)$ of 48 vessels.

Group 1. The average minimal lumen and reference diameters of 16 spastic segments in 13 patients at baseline, after administration of ergonovine and after administration of isosorbide dinitrate at the initial and follow-up tests are shown in Figure 1A. Coronary spasm was observed in 16 segments of 16 vessels in group 1: Minimal lumen diameter decreased after administration of ergonovine from $1.75 \pm 0.43$ to $0.55 \pm$ $0.40 \mathrm{~mm}$ during initial angiographic study and decreased from $1.57 \pm 0.44$ to $0.52 \pm 0.39 \mathrm{~mm}$ at follow-up. The minimal lumen and reference diameters of the remaining 23 nonspastic segments of 23 nonspastic vessels in group 1 are shown in Figure 1B. The response to ergonovine (minimal lumen diameter reduction) between the two tests was similar in these 23 nonspastic segments.

Group 2. Coronary spasm was observed in 23 segments at initial angiography (Fig. 2A). At follow-up, 13 of the 23 segments showed persistent vasospastic activity, but the remaining 10 segments showed no vasospasm. The minimal lumen and reference diameter changes for the remaining 25 segments of 25 vessels in group 2 are shown in Figure 2B. No spasm was observed at the initial test in these 25 segments, but at follow-up, 12 of the 25 exhibited vasospasm after ergonovine, and 13 had no vasospasm. An example of angiographic evidence of fluctuation in vasospastic location between initial and follow-up angiography in a patient in group 2 is shown in Figure 3.

\section{Discussion}

Quantitative coronary angiography and repeated ergonovine provocation tests demonstrated that in some patients with 
A

INITIAL TEST

(mm)

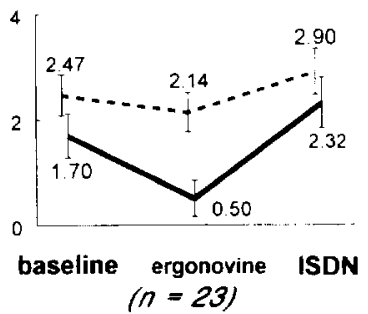

B

INITIAL TEST

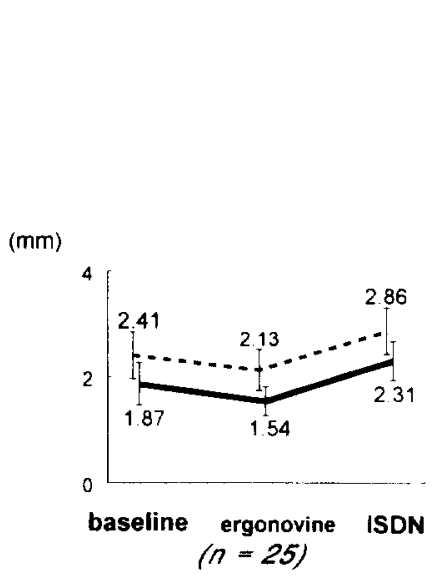

FOLLOW-UP TEST

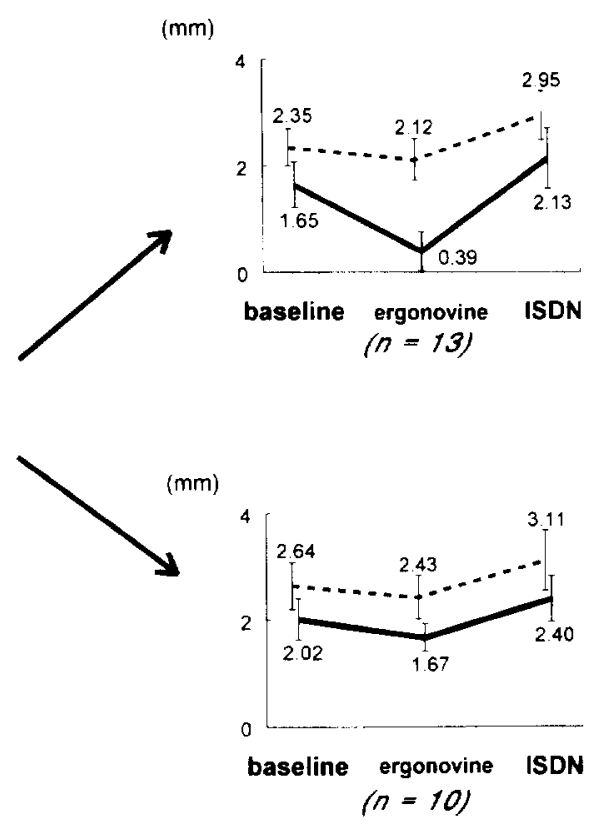

FOLLOW-UP TEST (mm)

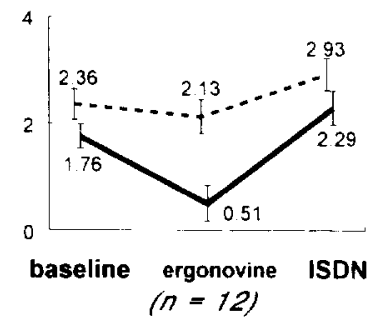

Figure 2. Reference (dotted line) and minimal lumen diameter (sclid line) changes at baseline and after administration of ergonovine and isosorbide dinitrate (ISDN) at initial and follow-up angiography in group 2. A, In 13 of the 23 initially spastic segments, minimal lumen diameter reduced from $1.65 \pm 0.44$ to $0.39 \pm$ $0.44 \mathrm{~mm}$ and vasospasm was again demonstrated at follow-up, whereas in the remaining 10 segments, vasospasm was not observed at follow-up. B, In 12 of the 25 initially nonspastic segments, minimal lumen diameter decreased from $1.76 \pm 0.23$ to $0.51 \pm$ $0.34 \mathrm{~mm}$ and vasospasm was demonstrated at followup, whereas in the remaining 13 segments, vasospasm was not observed at follow-up.

persistent variant angina, spasm may fluctuate from one vessel to another over a period of several years, whereas in others the location of coronary spasm is fixed over time.

Previous studies. Although several studies have reported the spontaneous remission of vasospastic angina (14-17), persistence of symptoms of variant angina has been reported in other studies with long-term follow-up of up to 10 years (17-20). Although Kaski et al. (21) recently reported the consistency of angiographic location of vasospasm in $10 \mathrm{pa}-$ tients with variant angina despite medical therapy, conflicting and indirect evidence from previous ECG studies $(14,22,23)$ suggests that the location and degree of coronary spasm may not be fixed. In a nonquantitative coronary angiographic study (18), we previously showed that percent diameter stenosis as assessed visually may fluctuate over time, although the relation of such relative measures to atherosclerosis was not explored. Waters et al. (14) reported that the location of myocardial ischemia indicated by ST segment changes at follow-up was similar to that at the initial ergonovine test. However, the direction of ST segment shifts (elevation or depression) changed in 3 of 10 patients who had repeated vasospastic attacks at follow-up. Previtali et al. (23) reported that difference of location of myocardial ischemia as determined by ST segment changes was observed in a single patient, yet the dose 

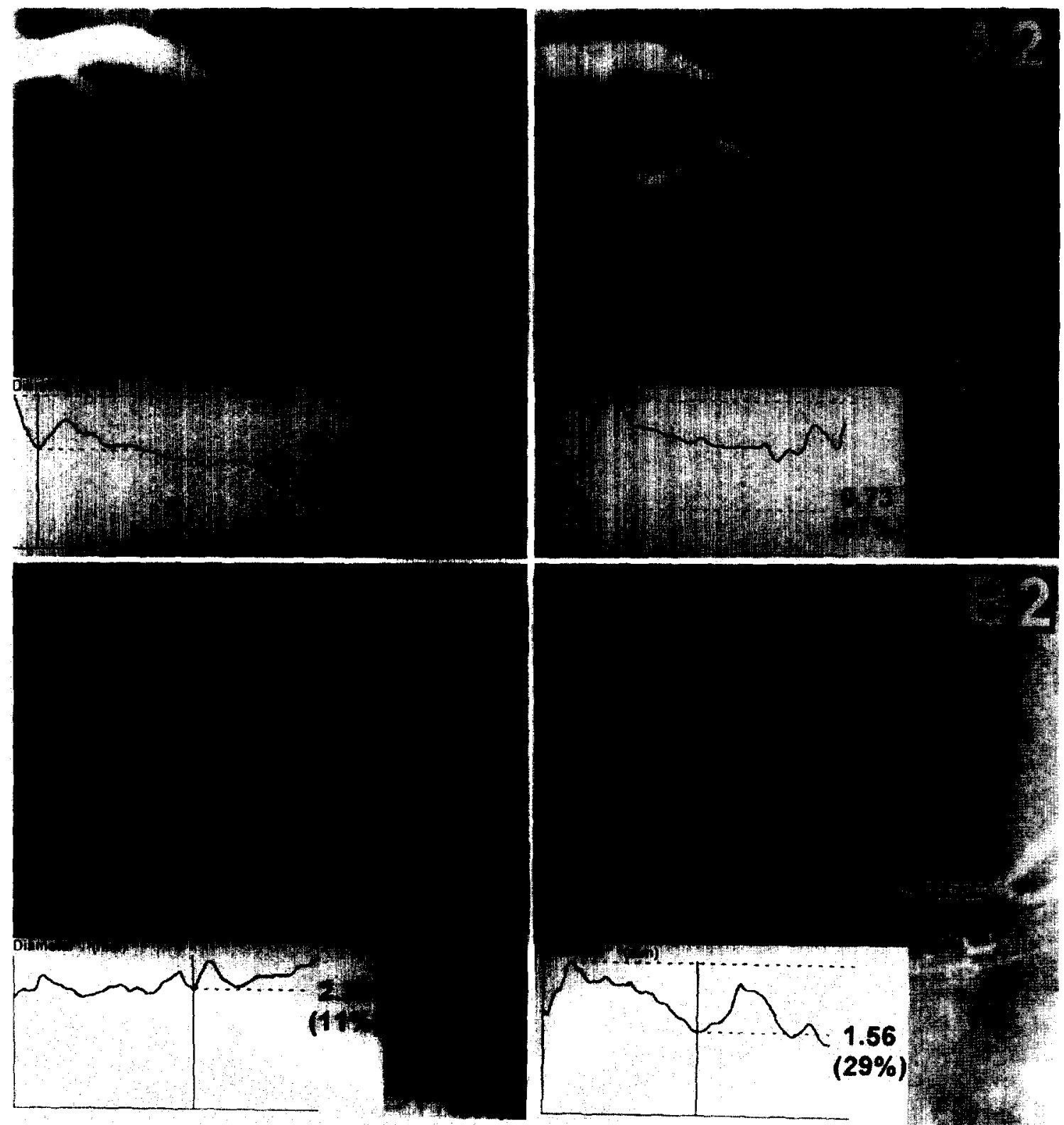

Figure 3. Initial and follow-up coronary angiograms and quantitative angiographic analysis from Patient 17, group 2. Angiograms A1, A2, C1 and $\mathbf{C} 2$ of the left anterior descending coronary artery were obtained in the right anterior oblique projection; angiograms B1, B2, D1 and D2 of the right coronary artery were obtained in the left anterior oblique projection. Initial angiograms were obtained at baseline (A1 and B1) and after administration of $0.2 \mathrm{mg}$ of intravenous ergonovine (A2 and B2). After administration of ergonovine, minimal luminal diameter decreased from 1.89 to $0.73 \mathrm{~mm}$, and a transient $67 \%$ lumen narrowing (coronary spasm) was observed in American Heart Association (AHA) segment 7 of the left anterior descending coronary artery (A2), and minimal lumen diameter decreased from 2.35 to $1.56 \mathrm{~mm}$, with no coronary spasm observed, in AHA segment 3 of the right coronary artery (B2). Follow-up angiograms $\mathbf{C 1}$ and $\mathbf{D} 1$ were obtained before (control) and angiograms $\mathbf{C} 2$ and $\mathbf{D} 2$ after $0.2 \mathrm{mg}$ of intravenous ergonovine. After administration of ergonovine, minimal luminal diameter decreased from 2.09 to $1.54 \mathrm{~mm}$, and no vasospasm was observed in AHA segment 7 of the left anterior descending coronary artery (C2), the site of previously observed spasm. However, in AHA segment 3 of the right coronary artery (D2), minimal lumen diameter decreased from 2.11 to $0.61 \mathrm{~mm}$, and a new, transient $75 \%$ lumen narrowing (vasospasm) was observed. (Figure 3 continued on page 1612 .)

of ergonovine required to induce vasospasm was different at follow-up in the majority of patients. Whittle et al. (22) reported that variable and unpredictable ECG responses to repeated ergonovine tests were observed in 6 of 10 patients. whereas the remaining 4 exhibited reproducible ECG re- sponses to ergonovine. Our quantitative coronary angiographic study clearly demonstrated that the location of coronary spasm was variable in some patients with persistent symptoms of angina. The variability of ECG changes seen during recurrent vasospastic angina attacks may be due to these phenomena. 


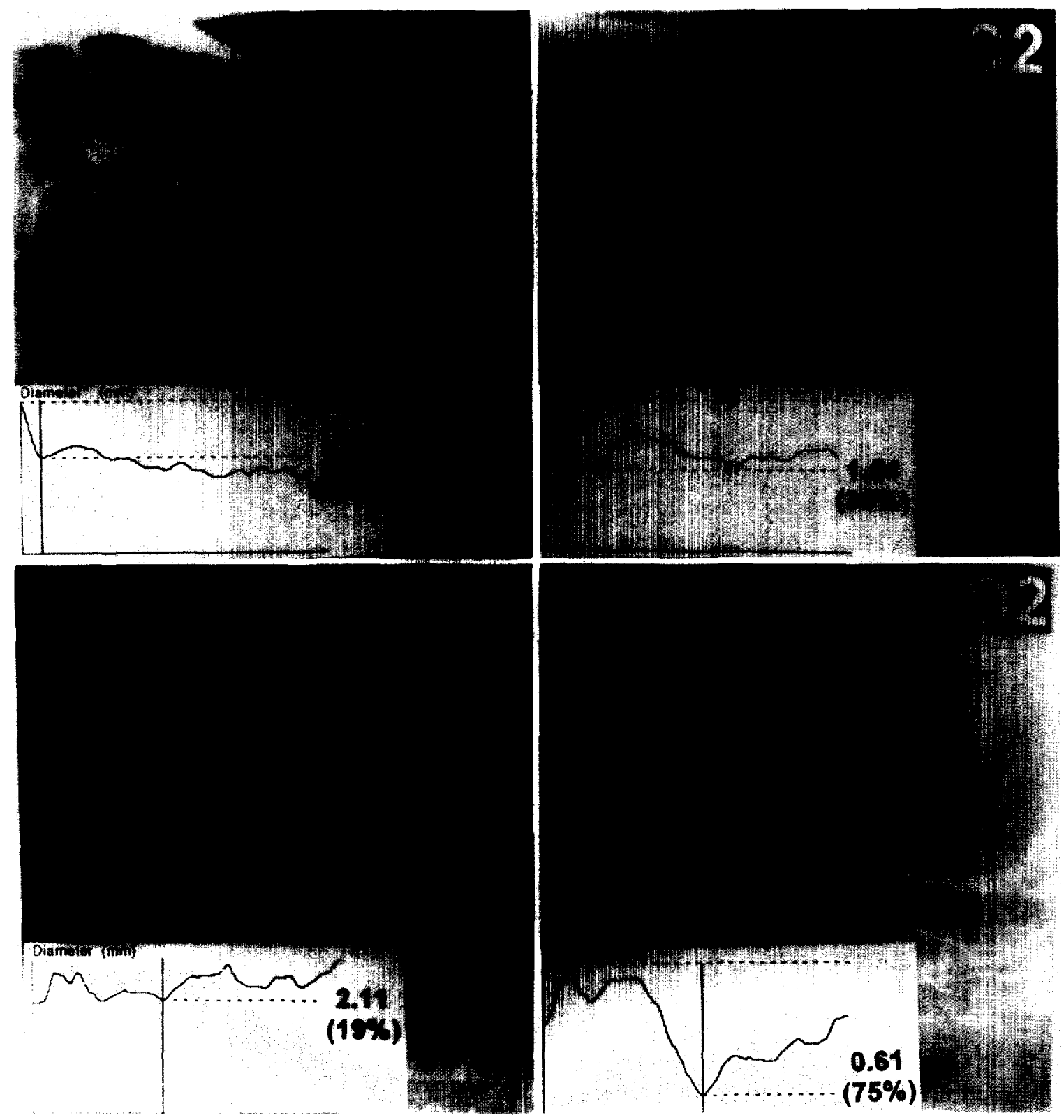

Figure 3. Continued

Proposed mechanism of spatial fluctuation of coronary spasm. The mechanism of fluctuation of vasospasm is still unknown. It has been proposed that the parasympathetic nervous system may play a role in the pathogenesis of variant angina (44), and variation in autonomic tone may therefore contribute to fluctuations in vasospastic behavior. Recent experimental studies (45-50) demonstrate that several endothelium-derived factors mediate vascular smooth muscle tone and that damaged endothelium may play a major role in the pathogenesis of vasospasm. Endothelial damage may occur even in the early stages of atherosclerosis (48-50). Zeiher et al. (51) indicated that abnormal vasoconstriction was observed in early atherosclerotic sites in patients without variant angina, using intracoronary ultrasound. Yamagishi et al. (52) reported that early stages of atherosclerosis were observed by intracoronary ultrasound at the site of spasm in patients with variant angina.

In our study, although the minimal lumen diameter of fixed stenosis tended to be smaller at follow-up than at the initial angiogram in 9 of 12 new spastic segments, in 8 of 10 previous spastic segments the minimal lumen diameter of fixed stenosis tended to be larger at follow-up. Both Waters et al. (53) and our group (54) recently reported that the standard deviation of repeated quantitative measurements with the CAAS system of serial clinical coronary angiograms is $\pm 0.20 \mathrm{~mm}$, and a difference greater than twice the standard deviation for repeated measurements of the CAAS system may represent a true change with $>95 \%$ confidence. If we adopt a per-lesion categoric approach to the definition of progression or regres- 
sion of atherosclerosis, we would include only lesions with a change $>0.40 \mathrm{~mm}$ at follow-up. If such a categoric approach were applied, then a significant progression occurred in group 2 with $95 \%$ confidence in 2 of 12 new spastic segments, and significant regression was not seen in any new spastic segments ( 0 of 12). Significant progression of fixed atherosclerosis was not observed in any previously spastic segments in which spastic activity was no longer provoked ( 0 of 10), and significant regression was seen in 2 of 10 previous spastic segments. If a continuous statistical approach is adopted in which the mean change in minimal lumen diameter is analyzed for the study group, we find that in Group 2 the minimal lumen diameter after administration of isosorbide dinitrate at new spastic segments was significantly smaller at follow-up than that at initial angiography $(2.44 \pm 0.32 \mathrm{~mm}$ initially vs. $2.29 \pm 0.30 \mathrm{~mm}$ at follow-up, $\mathrm{p}<0.05)$. However, the minimal lumen diameter in previous spastic segments, which demonstrated vasospasm at initial angiography but not at follow-up, was significantly larger at follow-up than at initial angiography (2.24 \pm $0.51 \mathrm{~mm}$ initially vs. $2.40 \pm 0.42 \mathrm{~mm}$ at follow-up, $\mathrm{p}<0.05$ ). Thus, if a continuous statistical approach is adopted for each study cohort, we observe that the development of spasm at a new site is associated with a reduction, and the disappearance of spasm with an improvement, in minimal lumen diameter after isosorbide dinitrate.

The present data lend support to the concept that fluctuation of spastic locations might relate to the pathologic process of local progression and regression of early atherosclerosis in coronary arteries. Clearly, a large prospective (and probably multicenter) trial with long-term angiographic follow-up and repeated ergonovine testing would be required to definitively establish this point.

Conclusions. Quantitative coronary angiography and repeated ergonovine provocation tests demonstrate that in some patients with persistent variant angina, spasm may fluctuate from one vessel to another over a period of several years, whereas in others the location of coronary spasm is fixed over time. Vasospastic angina may not only be a transient disease restricted in location, but may also be a persistent and variable condition involving multiple vessels over many years.

We gratefully acknowledge the dedication and contribution of Fumimaro Takatsu, MD, Yukio Shiga. MD, Masato Watarai, MD, Seiji Shimizu. MD, Atsusi Nishiyama, MD, Takeshi Suba. MSc and the staff of the catheterization laboratory at Anjo Kosei Hospital, Japan. In addition, we are grateful to the staft of the core angiographic laboratory at Cardialysis Rotterdam for their quantitative analysis of the coronary angiograms. We thank Eric Boersma, PhD for statistical analysis and Ken Lehmann, MD for helpful advice.

\section{References}

1. Maseri A, L'Abbate A, Persola A. e1 al. Coronary vasuspasm in angina pectoris. Lancet 1977:1:713-8

2. Oviva RB, Pott DE, Pluss RG. Coronary arterial spasm in Prinzmetal angina. Documentation by coronary arteriography. N Engl J Med 1973:288:745-51.

3. Chahine RA, Raizner AE. Ishimori T. Luchi RJ. McIntosh HD. Tho incidence and clinical implications of coronary artery spasm. Circulation $1975 ; 52: 972-8$.

4. Maseri A, Severi S, De Nes M, et al. Variant angina: one aspect of a continuous spectrum of vasospastic myocardial ischemia. Am J Cardiol 1978:42:1019-35

5. Cipriano PR, Koch FH, Rosenthal SJ, Baim DS, Ginsburg R, Schroeder JS. Myocardial infarction in patients with coronary artery spasm demonstrated by angiography. Am Heart J 1983;105:542-7.

6. Bertrand ME, Lablanche JM, Tilmant PY, et al. Frequency of provoked coronary arterial spasm in 1089 consecutive patients undergoing coronary arteriography. Circulation 1982;65:1299-306.

7. Conti CR, Feldman RL, Pepine CJ. Coronary artery spasm: prevalence, clinical significance, and provocative testing. Am Heart J 1982;103:584-8.

8. Maseri A, L'Abbate A, Baroldi G, et al. Coronary vasospasm as a possible cause of myocardial infarction: a conclusion derived from the study of "preinfarction" angina. N Engl J Med 1978;299:1271-7.

9. Waters DD, Szlacheic J, Miller D, Theroux P. Clinical characteristics of patients with variant angina complicated by myocardial infarction or death within 1 month. Am J Cardiol 1982;49:658-64.

10. Nakamura M, Takeshita A, Nose Y. Clinical characteristics associated with myocardial infarction, arrhythmia, and sudden death in patients with vasospastic angina, Circulation 1987;75:1110-6.

11. Mark DB, Califf RM, Morris KG, et al. Clinical characteristics and long-term survival of patients with variant angina. Circulation 1984;69:880-8.

12. Ozaki Y, Keane D, Serruys PW. Relationship of basal coronary tone and vasospastic activity in patients with variant angina: a quantitative angiographic study. Br Heart J. In press.

13. Ozaki Y, Keane D, Haase J, et al. Temporal variability and correlation with geometric parameters in vasospastic angina: a quantitative angiographic study. Eur Heart J 1994;15:61-7.

14. Waters DD, Szlachcic J, Theroux P, Dauwe F, Mizgala HF. Ergonovine testing to detect spontaneous remission of variant angina during long-term treatment with calcium antagonist drugs. Am J Cardiol 1981;47:179-84.

15. Cipriano PR. Koch FH, Rosenthal SJ, Schroeder JS. Clinical course of patients following the demonstration of coronary artery spasm by angiography. Am Heart J 1981:101:127-34

16. Waters DD, Bouchard A, Theroux P. Spontaneous remission is a frequent outcome of variant angina. J Am Coll Cardiol 1983;2:195-9.

17. Bott-Silverman C, Heupler FA. Natural history of pure coronary artery spasm in patients treated medically. J Am Coll Cardiol 1983;2:200-5.

18. Ozaki Y, Takatsu F, Osugi J, et al. Long-term study of recurrent vasospastic angina using coronary angiograms during ergonovine provocation tests. Am Heart J 1992;123:1191-8

19. Selzer A, Langston M. Ruggeroli C, Cohn K. Clinical syndrome of variant angina with normal coronary arteriogram. N Engl J Med 1976;295:1343-7.

20. Takenaga M, Ishiyama $Y$, Niina $H$, Koiwaya $Y$, Eto T. Recurrent vasospastic angina of more than thirteen years' duration. Am Heart J 1993;125:245-7.

21. Kaski JC. Tousoulis D, McFadden E, Crea F, Pereira WI, Maseri A. Variant angina pectoris: role of coronary spasm in development of fixed coronary obstructions. Circulation 1992;85:619-26.

22. Whittle JL, Feldman RL, Pepine CJ, Curry RC, Conti CR. Variability of electrocardiographic responses to repeated ergonovine provocation in variant angina patients with coronary artery spasm. Am Heart J 1982;103:161-7.

23. Previtali M. Panciroli C, Ponti RD, Chimienti M, Montemartini C, Salerno JA. Time-related decrease in sensitivity to ergonovine in patients with variant angina. Am Heart J 1989;117:92-9.

24. Heupler FA Jr, Proudfit WL, Razavi M, Shirey EK, Greenstreet R, Sheldon WC. Ergonovine maleate provocative test for coronary arterial spasm. Am J Cardiol 1978;41:631-40.

55. Schroeder JS, Bolen JL, Quint RA, et al. Provocation of coronary spasm with ergonovine maleate. New test with results in 57 patients undergoing coronary angiography. Am J Cardiol 1977;40:487-91.

26. Bertrand ME, Lablanche JM, Fourrier JL. Gommeaux A, Ruel M. Relation to restenosis after percutaneous transluminal coronary angioplasty to vasomotion of the distal coronary artery segment. Am J Cardiol 1989;63:277-81.

27. Curry RC, Pepine CJ, Sabom MB, Conti CR. Similarity of ergonovineinduced and spontaneous attacks of variant angina. Circulation 1979;59:30712.

28. Waters DD, Szlachcic J, Bonan R, Miller DD, Dauwe F, Theroux P. Comparative sensitivity of exercise, cold pressor and ergonovine testing in 
provoking attacks of variant angina in patients with active disease. Circulation 1983;67:310-5.

29. Kaski JC, Crea F, Meran D, et al. Local coronary supersensitivity to diverse vasoconstrictive stimuli in patients with variant angina. Circulation 1986;74: $1255-65$.

30. Lablanche JM, Leroy F, McFadden EP, Bauter C, Bertrand ME. Doseresponse curve of angiographically smooth human epicardial vessel segment to intracoronary injections of isosorbide dinitrate. J Cardiovasc Pharmacol $1992 ; 20: 473-8$

31. Lablanche JM, Delforge MR, Tilmant PY. Thieuleux FA, Bertrand ME Effets hêmodynamiques et coronaires du dinitrate d'isosorbide; comparison entre les voies d'injection intracoronaire et intraveineuse. Arch Mal Coeur 1982;75:303-15.

32. Gronenschild E, Janssen J, Tijdens F. CAAS II: a second generation system for off-line and on-line quantitative coronary angiography. Cathet Cardiovasc Diagn 1994;33:61-75.

33. Haase J, Escaned J, van Swijndregt EM, et al. Experimental validation of geometric and densitometric coronary measurements on the new generation cardiovascular angiography analysis system (CAAS II). Cathet Cardiovasc Diagn 1993;30:104-14.

34. Serruys PW, Booman F, Troost GJ, et al. Computerized quantitative coronary angiography applied to percutaneous transluminal coronary angioplasty: advantages and limitations. In: Kaltenbach M, Gruntzig A, Rentrop K. Bussmann WD, editors. Transluminal Coronary Angiography and Intracoronary Thrombolysis. Coronary Heart Disease IV. Berlin: SpringerVerlag, 1982:110-24.

35. Serruys PW, Foley DP, de Feyter PJ, editors. Quantitative Angiography in Clinical Practice. Dordrecht. The Netherlands: Kluwer, 1994.

36. Serruys PW, Luyten HE, Beatt KJ, et al. Incidence of restenosis after successful coronary angioplasty: a time-related phenomenon; a quantitative angiographic study in 342 consecutive patients at 1,2,3, and 4 months Circulation 1988;77:361-71.

37. Keane D, Haase J, Slager CJ, et al. Comparative validation of quantitative coronary angiographic systems. Results and implications from a multicenter study. Circulation 1995;91:2174-83

38. Ozaki Y, Keane D. Serruys PW. Progression and regression of coronary stenosis in the long-term follow-up of vasospastic angina: a quantitative angiographic study. Circulation 1995:92:2446-56.

39. Ozaki Y, Keane D, Herrman JP, et al. Coronary arteriography for quantitative analysis: an experimental and clinical comparison of cinefilm and video recordings. Am Heart J 1995;129:471-5.

40. Herrmann JP, Keane D, Ozaki Y, den Boer A, Serruys PW. Radiological quality of coronary guiding catheters: a quantitative analysis. Cathet Cardiovasc Diagn 1994;33:55-60.

41. Hermans WRM. Rensing BJ. Foley DP. et al. Therapeutic dissection after successful coronary angioplasty: no influence on restenosis on clinical outcome: a study in 693 patients. J Am Coll Cardiol 1992;20:767-80.

42. Keane D, Serruys PW. Quantitative coronary angiography: an integral component of interventional cardiology. In: Topol EJ, Serruys PW, editors. Current Review of Interventional Cardiology, 2nd ed. Philadelphia: Current Medicine, 1995:205-33.

43. American Heart Association Committee Report. A reporting system on patients evaluated for coronary artery disease. Circulation 1975;51:7-34.

44. Yasue H, Touyama M, Shimamoto M, Kato H, Tanaka S, Akiyama F. Role of autonomic nervous system in the pathogenesis of Prinzmetal's variant form of angina. Circulation 1974;50:534-9.

45. Vanhoutte PM, Shimokawa H. Endothelium-derived relaxing factor and coronary vasospasm. Circulation 1989;80:1-9.

46. Ganz P. Alexander W. New insights into the cellular mechanisms of vasospasm. Am J Cardiol 1985;56:11E-15E

47. Heistrad DD, Armstrong ML, Marcus ML, Piegors DJ, Mark AL. Augmented responses to vasoconstrictor stimuli in hypercholesterolemic and atherosclerotic monkeys. Circ Res 1984;61:711-8.

48. Shimokawa H, Tomoike H, Nabeyama S, Yamamoto H, Araki H, Nakamura M. Coronary artery spasm induced in atherosclerotic miniature swine. Science 1983;221:560-2.

49. Shimokawa $\mathbf{H}$, Tomoike H, Nabeyama S, et al. Coronary artery spasm induced in miniature swine: angiographic evidence and relation to coronary atherosclerosis. Am Heart J 1985;110:300-10.

50. Egashira K, Tomoike H, Yamamoto Y, Yamada A, Hayashi Y, Nakamura M. Histamine-induced coronary spasm in region of intimal thickening in miniature pigs: role of serum cholesterol and spontaneous or induced intimal thickening. Circulation 1986:74;826-37.

51. Zeiher AM, Schachinger V, Hohnloser SH, Saurbier B, Just H. Coronary atherosclerotic wall thickening and vascular reactivity in humans: elevated high-density lipoprotein levels ameliorate abnormal vasoconstriction in early atherosclerosis. Circulation 1994;89:2525-32.

52. Yamagishi M, Miyatake K, Tamai J, Nakatani S, Koyama J, Nissen SE. Intravascular ultrasound detection of atherosclerosis at the site of focal vasospasm in angiographically normal or minimally narrowed coronary segments. J Am Coll Cardiol 1994;23:352-7.

53. Waters DD, Lespérance J, Craven TE, Hudon G, Gillam LD. Advantages and limitations of serial coronary arteriography for assessment of progression and regression of coronary atherosclerosis; implication for clinical trials. Circulation 1993;87 Suppl II:II-38-47.

54. Foley DP, Deckers $\mathbf{J}$, van den Bos AA, et al. Usefulness of repeat coronary angiography 24 hours after successful balloon angioplasty to evaluate early luminal deterioration and facilitate quantitative analysis. Am J Cardiol $1993 ; 72: 1341-7$. 